\title{
THERMOMECHANICAL AND MORPHOLOGY OF BIODEGRADABLE FILM MADE OF TARO STARCH AND CHITOSAN PLASTICIZED BY CASTOR OIL
}

\author{
M. Hasan ${ }^{1, *}$, Zulfadli ${ }^{1}$, M. Nazar ${ }^{1}$, R.F.I. Rahmayani ${ }^{1}$, G. Fajri ${ }^{1}$ \\ and H. Fansuri ${ }^{2}$ \\ ${ }^{1}$ Department of Chemistry Education Universitas Syiah Kuala Darussalam 23111 \\ Banda Aceh, Indonesia. \\ ${ }^{2}$ Department of Chemistry, Institut Teknologi Sepuluh Nopember (ITS) Surabaya, Kampus ITS \\ Sukolilo, Surabaya 60111, Indonesia, \\ *E-mail: muhammadhasan.kimia@unsyiah.ac.id
}

\begin{abstract}
A biodegradable film made of taro starch and chitosan plasticized by castor oil was created through a casting solvent method. This study examined the influence of taro starch and chitosan composition on the thermo-mechanical and morphological properties of the film. We have successfully obtained a film with a smooth surface and compact structure of taro starch. The results showed that the higher proportion of chitosan in the polymer matrix succeeded in increasing the tensile strength and thermal stability of the film. The addition of chitosan into taro starch samples resulted in reducing the water uptake of the film. The film with a balanced ratio of taro and chitosan starch had excellent water resistance, its absorption of water is the lowest of all compositions.
\end{abstract}

Keywords: Biodegradable Film, Taro Starch, Chitosan, Castor Oil

(c) RASĀYAN. All rights reserved

\section{INTRODUCTION}

The increasing problem of plastic waste to the environment increases the awareness of researchers to develop biodegradable plastics to replace conventional non-biodegradable petrochemicals plastic materials for various applications. Starch is one of the most widely used biodegradable plastic raw materials due to its multiple advantages, including its biodegradability property, renewable, non-toxic, inexpensive, and abundantly available ${ }^{1-2}$. Starch can be found in various sources of cereals and tubers, such as rice, potatoes, corn, yam, wheat, cassava, and taro ${ }^{3}$.

Starch is a macromolecule consists of amylose and amylopectin where the relative ratio of each component highly depends on the starch source itself. Corn starch, for example, contains 28 percent of amylose while it is only 17 percent in cassava ${ }^{4}$. Taro starch contains amylose ranging from 22.8 to 35.7 percent depending on its variety ${ }^{5}$. The thermomechanical, film formation and physical properties bioplastics made of starch depend on the ratio of amylose to amylopectin in starch. The higher the proportion of amylose to amylopectin in the starch, the more prominent the properties mentioned above ${ }^{6}$. Some of the flaws of starch-based films are that it is fragile and hydrophilic. People believed that starch is hard to process and has very limited use ${ }^{7}$. Many studies have been conducted to overcome the problem i.e blending the starch with various compounds, such as adding $\mathrm{ZnO}$ nanoparticles and montmorillonite ${ }^{8}$, blending cassava starch with Low Linear Density Polyethylene (LLDPE) ${ }^{9}$, adding green tea extract and basil into the cassava starch matrix ${ }^{10}$, and forming composites using microcrystalline cellulose ${ }^{11}$. The other way to improve the thermomechanical properties of starch-based films is by adding chitosan.

Chitosan is the most widely available biopolymer in nature after cellulose. It is extracted by deacetylating the chitin found in the skin of shrimp, crabs and mushrooms. Many recent publications concerning the starch film formation report the addition of chitosan, especially blending chitosan with starch is aimed at Rasayan J. Chem., 12(3), 1390-1398(2019) http://dx.doi.org/10.31788/RJC.2019.1235326

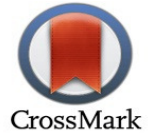


improvement of various characteristics of starch-based films. Some examples of blending are chitosanpumpkin starch ${ }^{12}$ and bio-composite of corn starch and chitosan ${ }^{13}$. In general, studies reported that the chitosan addition could improve the thermomechanical properties of starch films. However, the films are still rigid and fragile. Therefore, plasticizers are often added to the starch-chitosan matrix to improve the properties. They not only maintain the thermomechanical properties but also reduce the rigidness by increasing the film elasticity which, in turn, expanding the application of starch-based plastic films. Some common plasticizers that employed to increase the elasticity of starch-based films include glycerol, sorbitol, polyol, and essential oils ${ }^{14-19}$. However, to date, there is no publication concerning the use of taro starch and chitosan plasticized by castor oil. Thus, the paper reports the characteristics of the plastic films made of taro starch and chitosan using castor oil as the plasticizer. The major objective in this work was to study the influence of taro starch and chitosan composition on the thermo-mechanical and morphological properties of the film.

\section{EXPERIMENTAL}

\section{Material and Methods}

The taro starch was originated from Aceh, Indonesia. The pretreatment involved blending it to create a fine powder, which was then immersed in distilled water for 36 hours. The precipitate was then dried at $70{ }^{\circ} \mathrm{C}$ for 6 hours in an oven. The chitosan was purchased from Tokyo chemical industry co., Ltd. Japan; and the acetic acid was purchased from Sigma-Aldrich.

\section{Film Preparation}

The film preparation method refers to Hasan et $\mathrm{al}^{20}$ with a slight modification. The film was prepared by solvent evaporation where taro starch (TS) and chitosan $(\mathrm{CH})$ were initially weighed following the experimental design (Table-1) and later dissolved in $50 \mathrm{~mL}$ of 2 percent acetic acid while continuously stirred for $5 \mathrm{~h}$ at $70^{\circ} \mathrm{C}$. Next, castor oil was added, and the stirring continued for 45 minutes at $70^{\circ} \mathrm{C}^{12}$. The mixture was poured in a petri dish and left at room temperature for one hour prior to solvent evaporation at $75^{\circ} \mathrm{C}$ for 6-7 h. The film was then removed from the oven and cooled at room temperature.

Table-1: Experimental Design

\begin{tabular}{c|c|c}
\hline Sample & Weight of Chitosan $(\mathrm{g})$ & Weight of Taro Starch $(\mathrm{g})$ \\
\hline CH100 & 2,0 & 0,0 \\
\hline CH70TS30 & 1,4 & 0,6 \\
\hline CH50TS50 & 1,0 & 1,0 \\
\hline CH30TS70 & 0,6 & 1,4 \\
\hline TS100 & 0,0 & 2,0 \\
\hline
\end{tabular}

\section{Structure Analysis}

The structure of the bioplastic films product was analyzed using FTIR and XRD. FTIR spectra were obtained by Perkin Elmer 1800 series spectrometer and scanned in the wavenumbers ranging from 650 to $3900 \mathrm{~cm}^{-1}$. The crystallographic analysis was carried out using a Shimadzu X-ray diffractometer. A thin film was placed at the sample holder and measured by using $\mathrm{Cu}-\mathrm{K} \alpha$ radiation at the wavelength $(\lambda)$ of $0.1541 \mathrm{~nm}, 30 \mathrm{~mA}$ of electrical current, and accelerating voltage of $40 \mathrm{kV}$. The measurement was recorded with the scattering angle ranging from $10^{\circ}$ to $80^{\circ}$.

\section{The Analysis of Mechanical Properties}

The tensile strength analysis was carried out using IK Tester MCT-2150 and the analysis procedure referred to ASTM 0638. A sample of $4 \mathrm{x} 1 \mathrm{~cm}^{2}$ was prepared and conditioned beforehand to the standard room temperature and humidity $\left(23 \pm 2^{\circ} \mathrm{C}, \mathrm{RH}=52 \%\right)$ for $24 \mathrm{~h}$ and was pulled at the speed of $2 \mathrm{~mm} / \mathrm{min}$.

\section{The Analysis of Thermal Properties}

Thermal properties examination aimed at determining the film resistance to the thermal contact influence. Thermal properties analysis was measured by the DSC-TGA of Linseis STA PT1600. The film was heated with a rate of $10{ }^{\circ} \mathrm{C} / \mathrm{min}$ at the temperature between $25^{\circ} \mathrm{C}$ and $600^{\circ} \mathrm{C}$. 
RASĀYAN J. Chem.

Vol. 12 | No. 3 |1390 - 1398| July - September | 2019

\section{Microstructure Analysis Using Scanning Electron Microscopy (SEM) and Atomic Force Microscopy (AFM)}

SEM was utilized to examine the surface area of the films and AFM was used for topographic analysis. The film samples of $5 \times 5 \mathrm{~mm}^{2}$ were mounted on gold-coated aluminum stubs. It was then observed using an SEM tool of KYKY-EM3200 (Philip: XL30 model) and an acceleration voltage of $25 \mathrm{kV}$. The topographic analysis of the film surface was conducted using Multimode AFM.

\section{Water Uptake Test}

This test referred to a modified method developed by Martucci et al. ${ }^{21}$ and Chen et al. ${ }^{22}$. A film of 2 x 2 $\mathrm{cm}^{2}$ was weighed before being dipped in deionized water at room temperature. Subsequently, the film was periodically removed from the solution and was weighed to determine the water uptake using equation 1 :

$$
\text { Water Uptake }=\frac{W-W o}{W o} \times 100 \%
$$

$W_{o}$ and $W$ respectively represent the initial and final sample weight.

\section{Structural Analysis}

\section{RESULTS AND DISCUSSION}

Figure-1 shows the FTIR spectra of the functional groups of plastic films made of taro starch, chitosan, and castor oil while Table-2 presents the absorption peak analysis. The FTIR spectra of taro and chitosan starch films showed a typical absorption by functional groups of $\mathrm{OH}, \mathrm{NH}, \mathrm{CH}$ aliphatic, $\mathrm{C}=\mathrm{O}$ and $\mathrm{C}-\mathrm{O}$, in the starch and chitosan molecules with castor oil plasticizer.

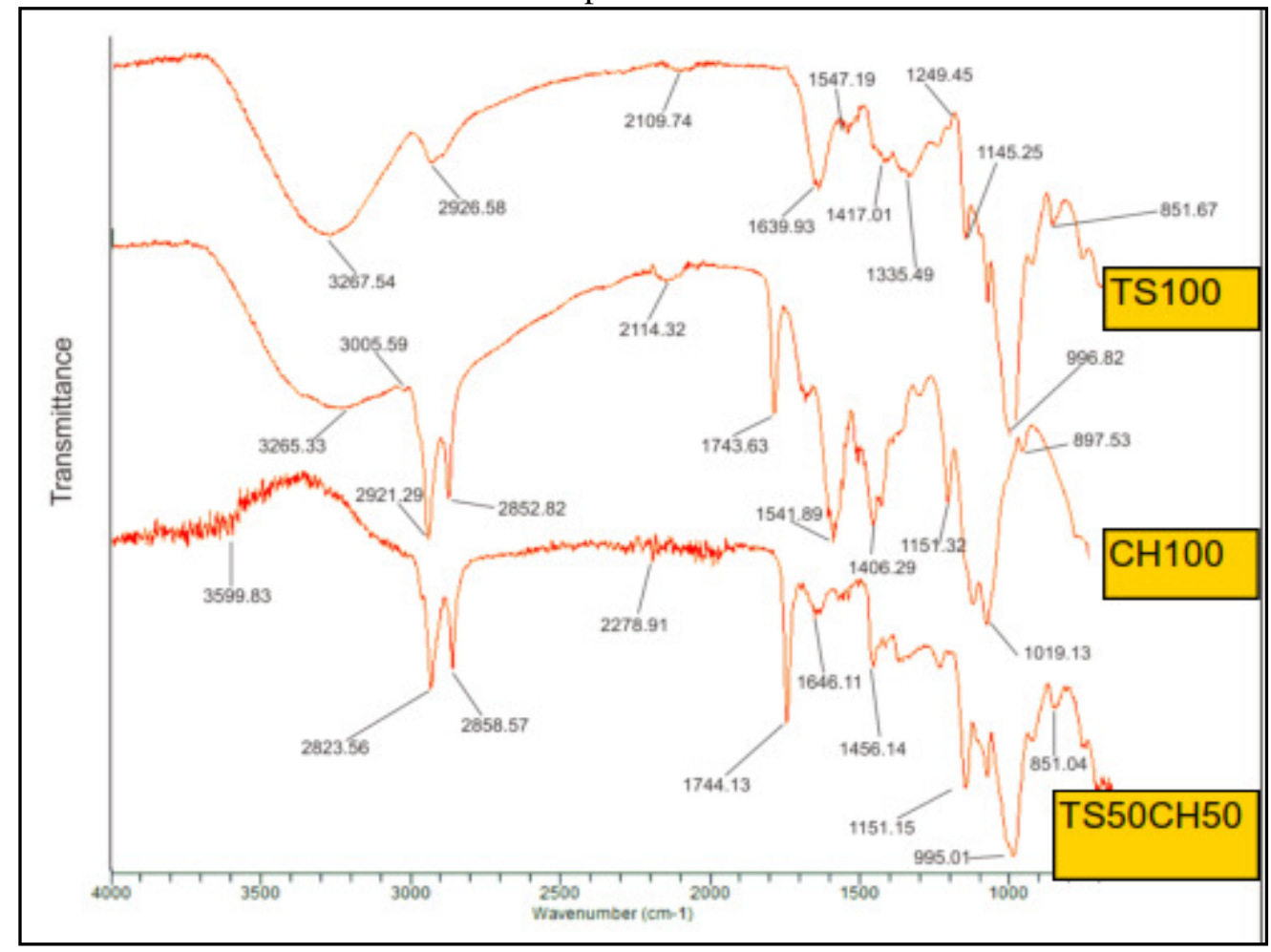

Fig.-1: FTIR Spectra of Film Taro Starch/Chitosan

The broad absorption peak of the $\mathrm{O}-\mathrm{H}$ group in the chitosan molecule was indicated in the area of $3265.33 \mathrm{~cm}^{-1}$, overlapping with the N-H group. The difference between the chitosan and starch was that chitosan had amine group that replaced the -OH group in amylose and amylopectin in starch. Another typical absorption distinguishing the chitosan and starch was the vibration of amine group at $1541.89 \mathrm{~cm}^{-1}$ and the C-N group at $1406.29 \mathrm{~cm}^{-1}$. The FTIR spectra of chitosan/taro starch indicate that no new 
RASĀYAN J. Chem.

Vol. 12 | No. 3 |1390 - 1398| July - September | 2019

functional group in the plastic films of taro starch and chitosan using castor oil as a plasticizer. The only change was the shift of absorption wavenumber by the same functional group. This means that only physical interaction through the hydrogen formation and van der Waals force ${ }^{23-24}$. The absorption appearance in the area of $1743 \mathrm{~cm}^{-1}$ was typical of $\mathrm{C}=\mathrm{O}$ carbonyl group, and the $\mathrm{C}-\mathrm{O}$ ester at $1166 \mathrm{~cm}^{-1}$ was resulted by free fatty acids of the addition of castor oil as a plasticizer.

Fig. 2 displays the XRD pattern of the taro starch and chitosan film. The diffraction pattern indicates that the taro starch has a semi-crystalline structure, and a broad diffraction peak which is a characteristic of an amorphous structure. There are also some sharp peaks at $2 \theta=13.7^{\circ}, 17.5^{\circ}$ and $24.5^{\circ}$ which are crystalline parts. The scattering peak at $13.7^{\circ}$ and $17.5^{\circ}$ indicates that taro starch has a Vh type crystal of the amylose complex ${ }^{4}$. The crystals were produced due to the presence of hydrogen bonds between the hydroxyl groups in the starch molecule chain and plasticizers. The peak at $13.7^{\circ}$ was the characteristics of B type crystals. This type of crystals can be formed during processing, especially those involving heating ${ }^{25}$. Similarly, the film made of chitosan formed a B type crystal, which is indicated by the scattering peak at $29.9^{\circ}$. The X-ray diffraction pattern of the sample mixture of starch and chitosan created a wide scattering peak in crystalline scattering region as respect to the interaction between the chains of starch and chitosan molecules that had modified the crystal structure of polymer molecules.

Table-2: Functional Group Analysis of Films by FTIR

\begin{tabular}{|c|c|c|c|}
\hline \multirow[t]{2}{*}{ Type of Vibration } & \multicolumn{3}{|c|}{ Wave Number $\left(\mathrm{cm}^{-1}\right)$} \\
\hline & TS100 & CH100 & TS50CH50 \\
\hline O-H stretching & 3267.54 & 3265.33 & 3599.83 \\
\hline C-H stretching & 2926,58 & 2921.29 & 2923.56 \\
\hline $\mathrm{C}=\mathrm{O}$ stretching & 1693,93 & 1743.63 & 1744,13 \\
\hline$-\mathrm{CH}_{2}$ - bending & 1335.49 & 1406.29 & 1456,14 \\
\hline $\begin{array}{l}\text { C-O stretching from } \\
\text { the ester group }\end{array}$ & 1145,25 & 1151,36 & 1151,15 \\
\hline$-\mathrm{NH}_{2}$ & - & 1636,99 & 1646,11 \\
\hline
\end{tabular}

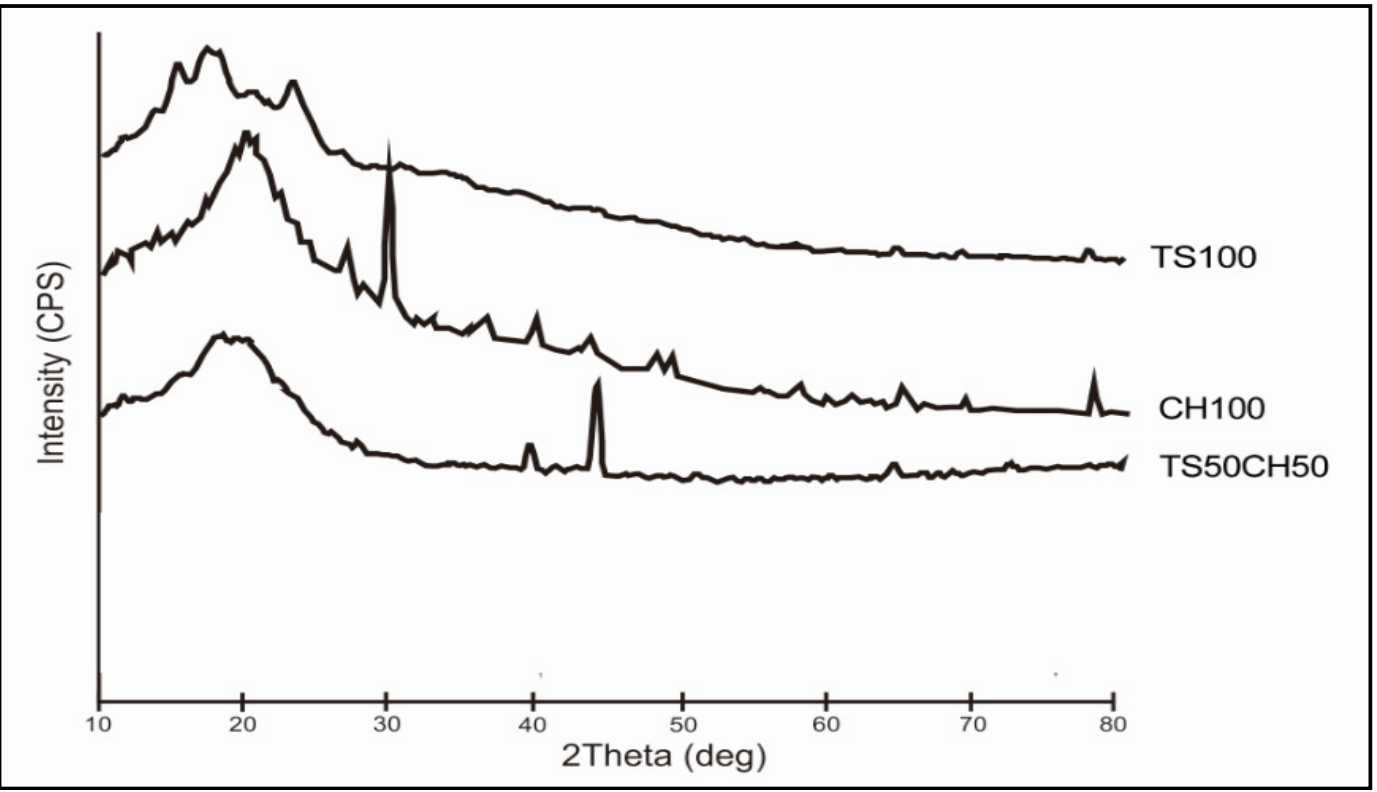

Fig.-2: XRD Pattern of the Film

\section{Mechanical Properties Analysis}

The test results of the mechanical properties of taro starch and chitosan films are presented in Table-3. The data indicated that tensile strength increased as the chitosan content rising, while the film elongation was more significant in those with a higher proportion of starch. This result is in line with several previous studies $^{26-28}$. The increasing ratio of chitosan in the polymer matrix influences the interaction between polymers through the mechanism of hydrogen bond formation between the amine group of the 
chitosan molecule chain and the hydroxyl group of starch molecules ${ }^{29-30}$. On the other hand, the increased chitosan will affect the formation of compact matrix structures resulting in the elongation value of plastic films to decrease ${ }^{31}$. The value is largely determined by how the polymer molecular chain easily moves, the easier the polymer molecule moves, the higher the elongation value.

Table-3: Mechanical Properties Result Test

\begin{tabular}{c|c|c|c}
\hline Sample & $\begin{array}{c}\text { Tensile Strength } \\
(\mathrm{MPa})\end{array}$ & $\begin{array}{c}\text { Elongation } \\
(\%)\end{array}$ & $\begin{array}{c}\text { Modulus Young } \\
(\mathrm{MPa})\end{array}$ \\
\hline TS70CH30 & $7.470 \pm 1.460$ & $18.905 \pm 2.696$ & $9.802 \pm 1.371$ \\
\hline TS50CH50 & $9.849 \pm 0.153$ & $14.028 \pm 0.685$ & $14.751 \pm 0.562$ \\
\hline TS30CH70 & $11.740 \pm 0.676$ & $17.716 \pm 0.033$ & $8.519 \pm 0.435$ \\
\hline
\end{tabular}

\section{Thermal Properties Analysis}

Thermal analysis data of the bioplastic films were shown in Fig.-3. The thermal degradation pattern of the bioplastic films seems to occur with a three stages mechanism. The first stage took place in temperature between 32.6 and $62.9^{\circ} \mathrm{C}$, used by the release of bound water molecules in the film matrix and other volatile components, resulting in 4.82 to 10.86 percent weight loss. The second stage occurred at the temperatures between 228.5 and $280{ }^{\circ} \mathrm{C}$ with 38.16 to 68.12 percent weight loss, concerning the decomposition of functional groups, i.e. amines and ethanol groups ${ }^{32}$. The final stage indicated weight loss ranging from 28.55 to $42.41 \%$, concerning the final decomposition due to the polymer molecular chain termination ${ }^{33}$.

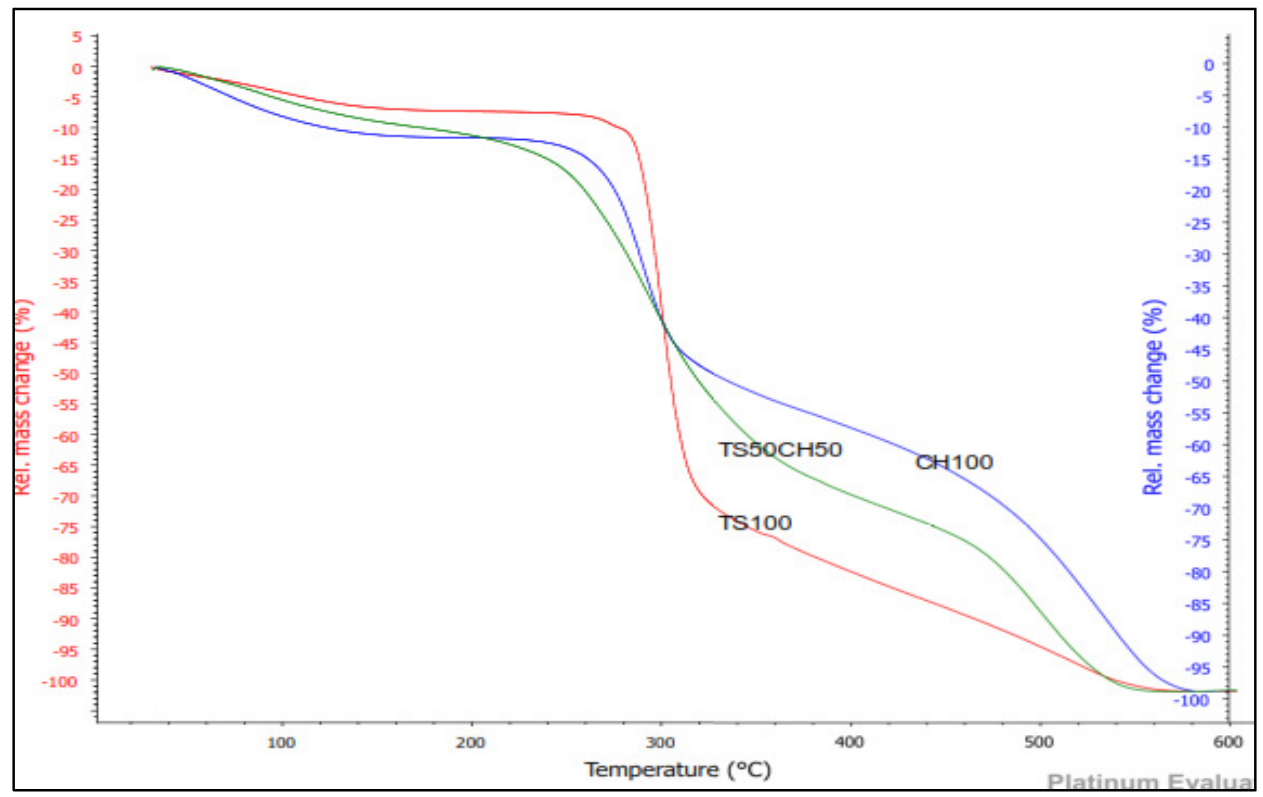

Fig.-3: TGA Curve of Bioplastic Film from Taro Starch and Chitosan

\section{Microstructure Analysis Using AFM}

Figure-4 presents the AFM images of taro and chitosan starch sample films on various compositions, and Table- 4 displays the surface roughness values. Figure- 4 and the value of surface roughness parameter, Ra and $\mathrm{Rq}$, show that chitosan films have higher surface roughness parameter values than other sample films. The particle size of chitosan contributed to this finding, while the $\mathrm{Ra}$ and $\mathrm{Rq}$ values of the taro starch and chitosan blend showed almost similar surface roughness that relatively low that can be considered as a smooth surface. Besides, the AFM image also proved that there was no phase separation between starch and chitosan. This finding is in line with the results of the SEM image (Fig.-5). Bonilla ${ }^{34}$ reported similar 
results concerning the surface of a film blending of wheat starch and chitosan. This means that the film produced is solid and as a result of the interaction between the starch and chitosan molecule chain. This data is supported by the data of FTIR measurements as well as thermal and mechanical properties.

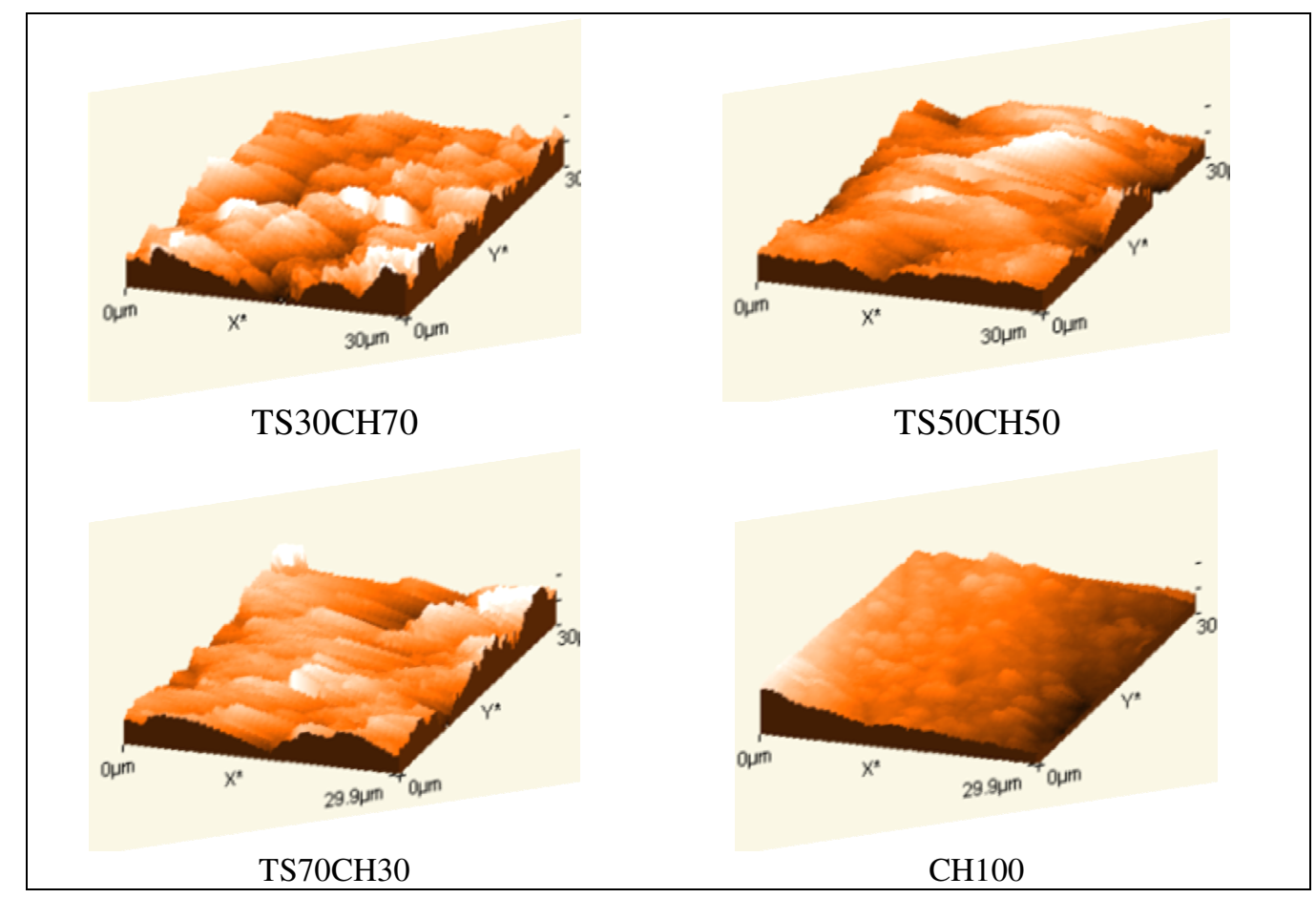

Fig.-4: AFM Image of Film TS/CH Topography

Table-4: Roughness Parameter and Water Uptake of the Film

\begin{tabular}{c|c|c|c}
\hline Sample & \multicolumn{2}{|c|}{ Roughness Parameter } \\
& $\mathrm{Ra}(\mathrm{nm})$ & $\mathrm{Rq}(\mathrm{nm})$ & $\begin{array}{c}\text { Water Uptake } \\
\text { (percent) }\end{array}$ \\
\hline TS100 & - & - & - \\
\hline TS70CH30 & 210 & 260 & 121.13 \\
\hline TS50CH50 & 220 & 280 & 87.80 \\
\hline TS30CH70 & 150 & 180 & 108.40 \\
CH100 & 730 & 850 & - \\
\hline
\end{tabular}

\section{Water Uptake Test}

The tests were carried out to examine the maximum ability of bioplastic films to absorb water. The data concerning water uptake measurements on bioplastic TS/CH films are shown in Table-4. The data indicates that the sample containing a higher proportion of taro starch had a very high water uptake due to the hydrophilic character of the starch. The film with an equal ratio of taro and chitosan starch had good resistance to water with the lowest water uptake was at 87.8 percent. This is attributed by the interaction between the hydroxyl groups of starch and chitosan to form a hydrophobic matrix structure ${ }^{34}$. The water uptake value reported in this study is relatively small compared to tapioca films who is ranging from 200 to 500 percent $^{35}$.

\section{CONCLUSION}

The study examined the influence of the composition of taro starch and chitosan additives using castor oil as a plasticizer. Films with a smooth surface have been successfully produced as evidenced by the AFM images (Fig.-3) with the relatively low $\mathrm{Ra}$ and $\mathrm{Rq}$ values for all films made of taro starch and chitosan. The polymer films produced have a compact structure, indicated by the FTIR spectra and the results of mechanical properties test. The higher proportion of chitosan in the polymer matrix corresponds to the higher tensile strength. However, the film elongation is getting smaller. Thermal stability of the films also improves as chitosan proportion increasing, indicated by a decrease in the weight loss of the samples 
RASĀYAN J. Chem.

Vol. 12 | No. 3 |1390 - 1398| July - September | 2019

compared to taro starch to the temperature above 200 degrees Celsius. Adding chitosan into taro starch samples has successfully reduced film water uptake, the films made of an equal ratio of taro starch and chitosan have good water resistance, showing the lowest water uptake among all compositions.
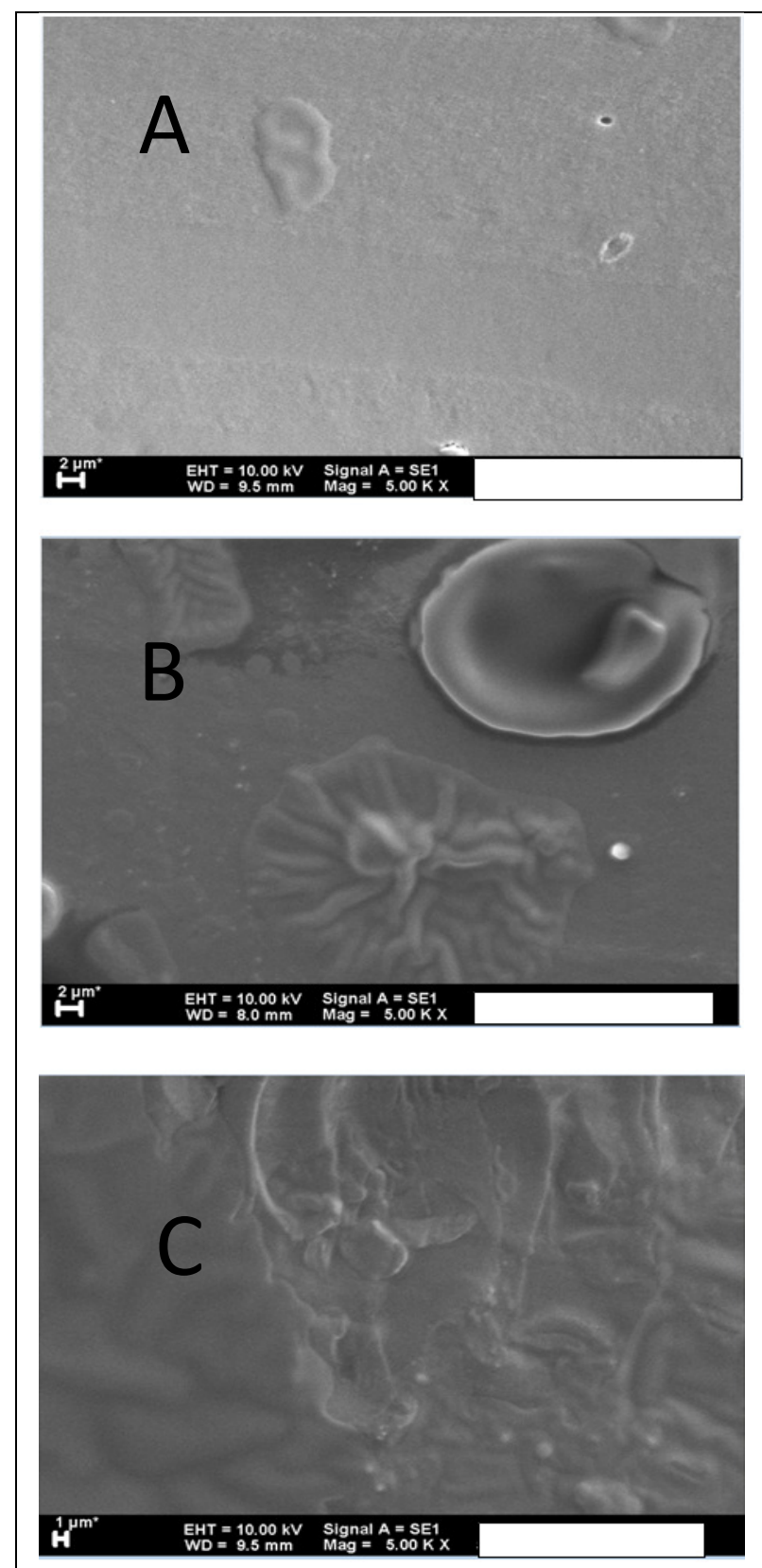
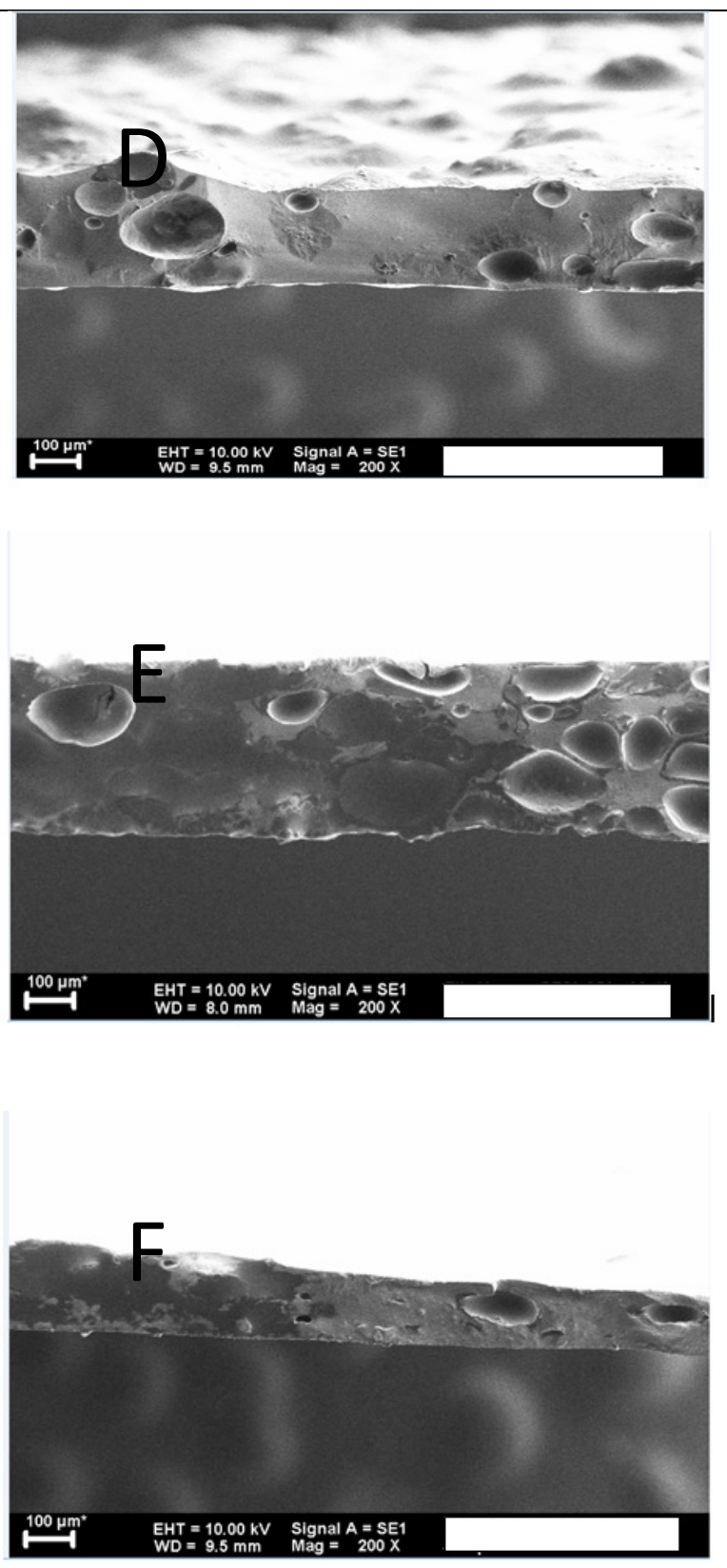

Fig.-5: SEM Image, A-C: Surface Image of Sample CH100, CH50TS50, TS100, D-F: Fracture Image of Sample CH100, CH50TS50, TS100

\section{REFERENCES}

1. A. Assatory, M. Vitelli, A.R. Rajabzadeh, R.L. Legge, Trends Food Sci. Technol.., 86, 340(2019), DOI: $10.1016 / \mathrm{j} /$ tifs.2019.02.006

2. S. Tabasum, M. Younas, M.A. Zaeem, I. Majeed, K.M. Zia, Int. J. Biol. Macromol., 122, 969(2019), DOI: $10.1016 /$ j.ijbiomac.2018.10.092

3. T. Woggum, P. Sirivongpaisal, T. Wittaya, Food Hydrocoll, 50, 54(2015), DOI: 10.1016/j.foodhyd.2015.04.010 
4. J.F. Mendes, R.T. Pashoalin, V.B. Marcona, A.R.S. Neto, A.C.P. Marques, J.M. Marconini, L.H.C. Mattoso, E.S. Mudeiros, J.E. Olivera, Carbohydr. Polym., 137, 452(2016), DOI: 10.1016/j.carbpol.2015.10.093

5. Y.N. Njintang, C.M.F. Mbofung, G.K. Moates, M.L. Parker, F. Craig, A.C. Smith, W.K. Waldron, J. Food Eng., 82, 114(2007), DOI: 10.1016/j.jfoodeng.2006.12.023

6. S. Khalid, L.Yu, M.Feng, L.Meng, Y.Bai, A.Ali, H.Liu, L.Chen, J. Food Pack. Shelf Life, 18, 71(2018), DOI: 10.1016/j.fpsl.2018.08.008

7. O. Lopez, M.A. Garcia, M.A. Villar, A. Gentili, M.S. Rodriguez, L. Albertengo, LWT-Food Sci. Technol., 57, 106(2014), DOI: 10.1016/j.lwt.2014.01.024

8. K. Vaezi, G. Asadpour, H. Sharifi, Int. J. Biol. Macromol., 124, 519(2019), DOI: 10.1016/j.ijbiomac.2018.11.142

9. D.M. Nguyen, T.V. Vi Do, A-C. Grillet, H.H.T huc, C.N.H. Thuc, Int. Biodeterior. Biodegrad., 115, 257(2016), DOI: 10.1016/j.ibiod.2016.09.004

10. C. Medina-Jaramillo, O. Ochoa-Yepes, C. Bernal, L. Fama, Carbohydr. Polym., 176, 187(2017), DOI: $10.1016 /$ j.carbpol.2017.08.079

11. J. Chen, F. Chen, Y. Meng, S. Wang, Z. Long, Polymer, 168, 228(2019), DOI: 10.1016/j.polymer.2019.02.026

12. M. Hasan, R.F.I. Rahmayani, Munandar, IOP Conf. Ser; Mat.Sci.Eng., 333, 01287(2018), DOI: 10.1088/1757-899X/333/1/012087

13. L. Ren, X. Yan, J. Zhou, J. Tong, X. Su, Int. J. Biol. Macromol., 105, 1636(2017), DOI: 10.1016/j.ijbiomac.2017.02.008

14. P. Zhang, Y. Zhou, Q. Shi, Carbohydr. Polym., 153, 345(2016), DOI: 10.1016/j.carbpol.2016.07.082

15. I. Arvanitoyannis, A. Nakayama, S. Aiba, Carbohydr. Polym., 36, 105(1998), DOI: 10.1016/S01448617(98)00017-4

16. M. Mondragon, K. Arroyo, J. Romero-Garcia, Carbohydr. Polym., 74, 201(2008), DOI: 10.1016/j.carbpol.2008.02.004

17. A.L. Da Roz, M.D. Zambon, A.A.S. Curvelo, A.J.F. Carvalho, Ind.Crop.Prod., 33, 152(2011), DOI: 10.1016/j.indcrop.2010.09.015

18. M.A. Shirai, M.V.E. Grossmann, S. Mali, F. Yamashita, P.S. Garcia, C.M.O. Muller, Carbohydr. Polym., 92, 19(2013), DOI: 10.1016/j.carbpol.2012.09.038

19. T.O. Siyanbela, A.F. Akinsola, O.R. Obanla, A.A. Adebisi, A.A. Akinsiku, I.O. Olanweraju, K.O. Ogunniran, O.S. Taiwo, K.O. Ajanaku, O.A. Bamgboye, Rasayan J.Chem., 10, 1003(2017), DOI: 10.7324/RJC.2017.1031811

20. M. Hasan, E.W.N. Chong, S. Jafarzadeh, M.T. Paridah, D.A. Gopakumar, H.A. Tajaruddin, S. Thomas, H.P.S. Abdul Khalil, Polymers, 11, 210(2019), DOI:10.3390/Polym11020210

21. J.F. Martucci, R.A. Russeckaite, J. Food Eng., 99, 377(2010), DOI: 10.1016/j.jfoodeng.2010.02.023

22. B.J. Chen, M-J. Chi, S. Cui, S-X. Hao, T. Zhau, Int. J. Biol.Macromol., 92, 715(2016), DOI: 10.1016/j.ijbiomac/2016.05.086

23. O.A. Silva, G.P. Michelly, G.P. Matheus, J. Caetano, D.C. Dragunski, Int. J. Biol. Macromol., 128, 290(2019), DOI:10.1016/j.ijbiomac.2019.01.132

24. K.M. Dang, R. Yoksan, Carbohydr. Polym., 115, 575(2015), DOI: 10.1016/j.carbpol.2016.04.113

25. K.Y. Castrejon-Parga, H. Camacho-Montes, C.A. Rodrigueaz-Gonzalez, C. Valesco-Santos, A.L. Martinez-Hernandez, D. Bueno-Jaquez, J.L. Rivera-Armenta, C.R. Ambrosio, C.C. Conzalez, M.E. Mendoza-Duarte, P.E. Garcia-Casillas, J. Alloys compd., 615, s505(2014), DOI: 10.1016/j.jallcom.2013.12.269

26. M.J. Bof, V.C. Bordagaray, D.E. Locaso, M.A. Garcia, Food Hydrocoll., 51, 281(2015), DOI: 10.1016/j.foodhyd.2015.05.018

27. C.C.S. Coelho, M.A. Cerqueira, R.N. Pereira, L.M. Prastana, O. Freitas-Silva, A.A. Vicente, L.M.C. Cabral, T.A. Texeira, Carbohydr. Polym., 174, 1181(2017), DOI: 10.1016/j.carbpol.2017.07.007 
28. W. Huo, G. Xie, W. Zhang, W. Wong, J. Shan, H. Liu, X. Zhou, Int. J. Biol. Macromol., 87, 114(2016), DOI: 10.1016/j.ijbiomac.2016.02.049

29. S. Jothibasu, S. Mohanamurugan, A. Vinod, Rasayan J.Chem., 11, 1255(2018), DOI: 10.31788/RJC.2018.1133096

30. M. Hasan, D.A. Gopakumar, V. Arumughan, Y.B. Pottathara, K.S. Sisanth, D. Pasquini, M. Bracic, B. Seantier, A. Nzihou, S. Thomas, S. Rizal, H.P.S. Abdul Khalil, Polymers, 11, 495(2019), DOI: $10.3390 /$ polym11030495

31. E.T. Kata, T. Trifkovic, V.A. Nedovic, B.M. Bugarski, M. Vargas, A. Chiralt, C. GonzalezMartinez, Carbohydr. Polym., 157, 1153(2017), DOI: 10.1016/ j.carbpol.2017.07.067

32. R. Priyadarshi, Sauraj, B. Kumar, Y.S. Negi, carbohydr. Polym., 195, 329(2018), DOI: 10.1016/j.carbpol.2018.04.089

33. J. Bonilla, L. Atares, M. Vargas, A. Chiralt, J. Food Eng., 114, 303(2013), DOI: 10.1016/j.jbiodeng.2012.08.005

34. D.P.B. Raja, B.S.J. Retnam, G.A.S. Prabu, A.A. Sundaram, Rasayan J.Chem., 11, 990(2018), DOI:10.31788/RJC.2018.1133048

35. S.W. Abdul Gani, A. Abu Bakar, S.A. Samsudin, J. Plast. Film Sheet., 32, 140(2016), DOI: $10.1177 / 8556087915590189$

[RJC-5326/2019] 